\title{
Response of the Black Sea ecosystem to the Chernobyl nuclear accident
}

\author{
Gennady G. Polikarpov*, Viktor N. Egorov \\ Department of Radiation and Chemical Biology, Kovalevsky Institute of Biology of the Southern Seas, Sevastopol 99011, Ukraine
}

\begin{abstract}
The most serious accident in a nuclear power plant to date occurred on April 26, 1986, at Chernobyl (Ukraine). Roughly $2 \%$ of the total fallout was deposited in the Black Sea basin. We summarize our views regarding the ecological consequences, based on a collective monograph (Polikarpov et al. 2008: Radioecological response of the Black Sea to the Chernobyl accident; in Russian). Radionuclide runoff into the Black Sea continues to this day, but long-term radioecological effects are minor, except for increased radionuclide levels in the sediments of several estuaries.
\end{abstract}

KEY WORDS: Radiology $\cdot$ Radioecology $\cdot$ Radioactive tracers $\cdot$ Anthropogenic impact

Resale or republication not permitted without written consent of the publisher

The response of the Black Sea ecosystem to the radionuclides released through the accident at the Chernobyl Nuclear Power Plant (CNPP), i.e. effects of ionizing radiation on the ecosystem, have been studied since 1986; a recent monograph (Polikarpov et al. 2008) assesses radioecological processes in the Black Sea in the context of natural environmental processes, anthropogenic impacts and climate change, and considers the importance of eco-ethics and eco-centrism in radiation protection of the biosphere in light of the principles of biodiversity conservation and sustainable development (UN 1992, Kinne 1997; see also Bréchignac 2008, Carol 2008).

Principal facts. The Black Sea and its basin were contaminated with CNPP radionuclides in May 1986 by atmospheric fallout and subsequent runoff of the Dnieper, Danube and other rivers; roughly $2 \%$ of the radionuclides released in the accident entered the Black Sea basin (Fig. 1). Radionuclide runoff from the vast catchment area of the Dnieper River continues to the present. The Black Sea aquatic environment and its biocenoses were capable of coping with the flux of CNPP radionuclides; these were transferred into Black Sea bottom sediments or to waters of the Mediterranean Sea. Concentrations of all long-lived radionuclides in organisms and in the aquatic environment were lower than the maximum permissible concentrations based on cytogenetic criteria.

Increased concentrations of long-lived radionuclides of $\mathrm{Cs}, \mathrm{Sr}$ and $\mathrm{Pu}$ in the aquatic environment led to bioaccumulation in marine organisms. Concentration factors of marine plants and animals remained constant, i.e. they did not depend on exposure time and environmental radionuclide concentrations. Concentration factors of every radionuclide coincided with values obtained in tracer experiments. This regularity simplifies radioecological assessments. A similar rule held for distribution factors for bio-inert and inert components.

The following radioecological zones were defined on the basis of the doses of chronic irradiation in water bodies: (1) 'Ecological masking zone', consisting of the CNPP cooling water pond, where organisms receive considerable irradiation, but where there are no destructive effects on the ecosystem. (2) 'Physiological masking zone', covering the Kiev Reservoir ecosystem, where radiobiological effects remained within the range of normal physiological fluctuations and thus may be masked. (3) 'No-effect zone', which includes the ecosystems of the Kakhovskaya Reservoir on the Dnieper River, the Northern Crimean Canal, and the Black and Aegean seas; 


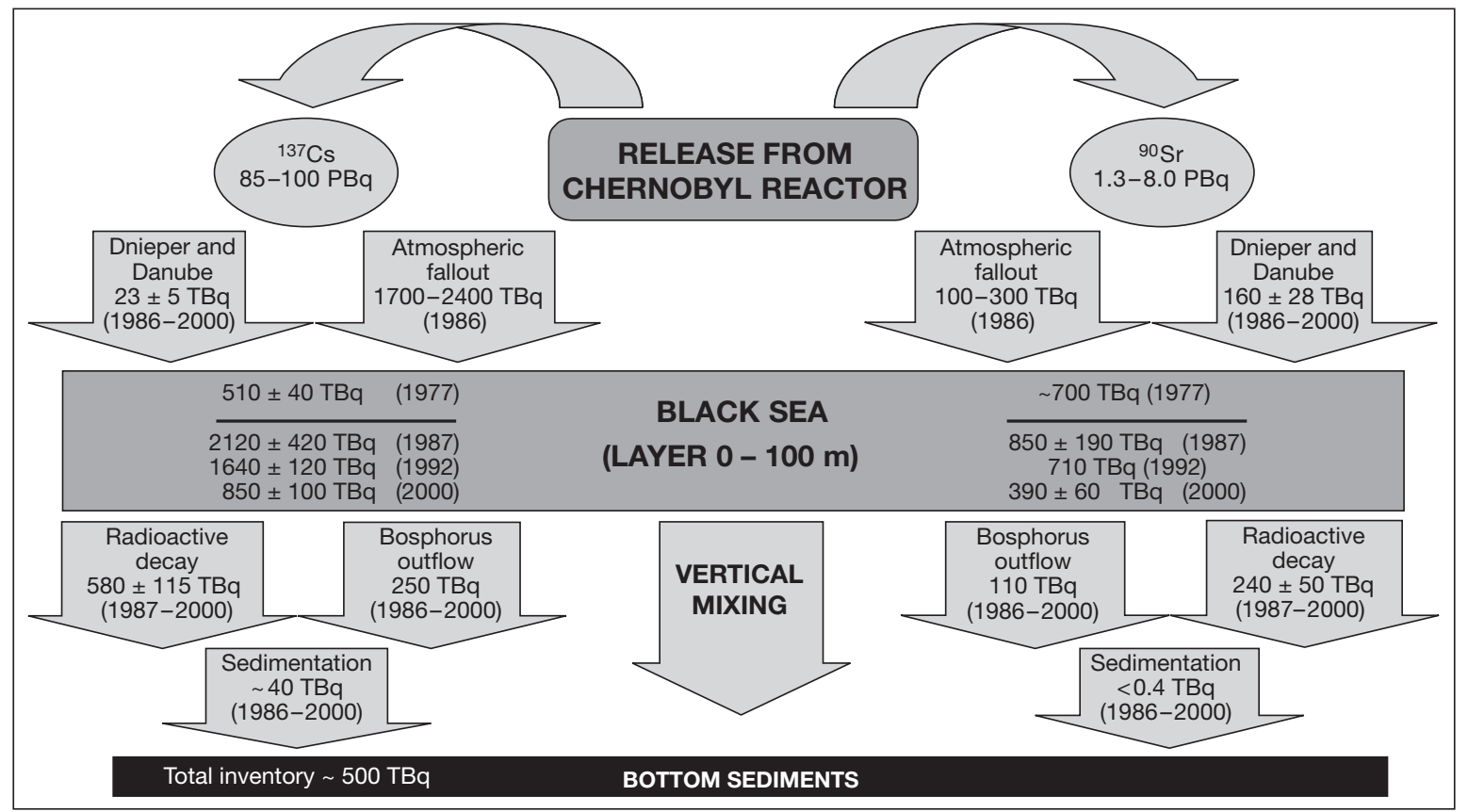

Fig. 1. Fate of Cs and Sr radioisotopes released in the Chernobyl accident in 1986. Arrows: fluxes in the Black Sea basin; boxes: total quantity in the upper layer of the Black Sea water column and in bottom sediments

radiobiological effects were not detected against the background of cosmic and other natural irradiation.

Transfer of radionuclides from the aquatic environment to organisms and sediments occurred throughout the study period (1986 to 2008) in the entire Black Sea basin. Radionuclide runoff continues, mainly from the CNPP cooling water pond to the Pripyat River and the Dnieper reservoirs, and further to the Black and Aegean seas. Radionuclides from the CNPP accident were found to be a highly precise radioactive tracer of biogeochemical and bio-hydrocenological processes in the marine ecosystem. Chernobyl radionuclides also represent a radioactive tracer of sedimentation processes; in addition, natural radioelements in the Black Sea restoration zone enabled the compilation of a chronology of events from the time of the joining of the Black and Mediterranian Seas and to the present.

From the information available we conclude: Radionuclide concentrations in the aquatic environment, bottom sediments and living components of ecosystems decreased exponentially from 1986 to 2008. Residence time of ${ }^{137} \mathrm{Cs}$ and ${ }^{90} \mathrm{Sr}$ in the aquatic environment was 25 to $40 \%$ of the lifetime of $97 \%$ of their atoms, as a result of interactions of oceanographic, biogeochemical and biohydrocenologic processes (as well as radioactive decay). This characterizes the self-cleaning capacity of the aquatic environment by (1) transfer of radionuclides from the water column to bottom sediments, and (2) outflow to the Mediterranean Sea. It provides a basis for the sustainable use of Black Sea resources.
Radioecological problem zones exist in the Dnieper and Bug estuaries and near the Danube Estuary, as well as in some smaller estuaries, as a result of increased radionuclide levels in bottom sediments. These estuaries require permanent (1) radioecological monitoring of radionuclide concentrations, and (2) radiation-ecological monitoring of ionizing radiation doses.

\section{LITERATURE CITED}

Bréchignac F (2008) Current challenges to the radiological protection of the environment: arguments for an ecosystem approach. Proc Int Conf on Radioecology and Environmental Radioactivity 15-20 June, 2008, Bergen, Norway, Part 1. Norwegian Radiation Protection Authority, Østerås, p 7-10

Carol S (2008) Radiological protection of the environment from an NGO perspective. Proc Int Conf on Radioecology and Environmental Radioactivity 15-20 June, 2008, Bergen, Norway, Part 2. Norwegian Radiation Protection Authority, Østerås, p 473-476

Kinne O (1997) Ethics and eco-ethics. Mar Ecol Prog Ser 153:1-3

Polikarpov GG, Egorov VN, Gulin SB, Stokozov NA and others (2008) Radioecological response of the Black Sea to the Chernobyl accident. ECOSEA-Hydrophysics, Sevastopol (in Russian; English abstract and table of contents)

UN (1992) General Assembly, United Nations. Rio Declaration on Environment and Development, Annex I A/Conf. 151/26 (Vol. I). UN Conference on Environment and Development, 3-14 June 1992, Rio de Janeiro. United Nations, New York, p 3-9 